\title{
CONDIÇÕES DE TRABALHO DOCENTE E SAÚDE NA BAHIA: ESTUDOS EPIDEMIOLÓGICOS
}

\author{
TÂNia Maria de Araújo* \\ Fernando Martins Carvalho ${ }^{* *}$
}

\begin{abstract}
RESUMO: As condições de saúde e trabalho de professores foram analisadas a partir de resultados de oito estudos epidemiológicos desenvolvidos no estado da Bahia. Os estudos, realizados em docentes baianos, de 1996 a 2007, determinaram as prevalências dos três principais grupos de queixas de saúde (problemas vocais, problemas osteomusculares e saúde mental) e as associaram a características da organização do trabalho docente. Os estudos revelam as importantes contribuiçóes dos aspectos relacionados ao ambiente escolar e à organização do trabalho docente para a ocorrência dos diferentes efeitos sobre a saúde investigados. Apesar do caráter exploratório desses estudos, sua análise conjunta permitiu evidenciar que docentes com trabalhos envolvendo alta exigência também apresentavam prevalências mais elevadas de queixas de doença. Esses resultados apontam para a necessidade do estabelecimento de políticas voltadas para a prevenção e atenção à saúde dos docentes.
\end{abstract}

Palavras-chave: Condiçôes de trabalho docente. Disfonia. Saúde mental. Distúrbios osteomusculares. Saúde de professores. Bahia.

WORK CONDITIONS AND HEALTH OF TEACHERS IN THE STATE OF BAHIA, BRAZIL: EPIDEMIOLOGICAL STUDIES

ABSTRACT: Teacher's work and health conditions were analyzed on the basis of results coming from eight epidemiological studies carried

* Doutora em Saúde Pública e professora do Departamento de Saúde da Universidade Estadual de Feira de Santana (UEFS). E-mail: araujo.tania@uefs.br

** Doutor em Saúde Pública e professor do Departamento de Medicina Preventiva e Social da Universidade Federal da Bahia (UfBA).E-mail: fmc@ufba.br

Educ. Soc., Campinas, vol 30, n. 107, p. 427-449, maio/ago. 2009

Disponível em <http://www.cedes.unicamp.br> 
out in the State of Bahia, Brazil. The studies among teachers, performed from 1996 to 2007, have determined the prevalence of the three main groups of health complaints (voice problems, musculoskeletal problems, and mental health problems) and tried to associate them to characteristics of teacher's work organization. The studies revealed important contributions of the aspects related to school work environment and teachers' work organization to the occurrence of the negative health effects investigated. Inspite of the exploratory approach of these studies, the joint analysis of data showed that teachers in high strain jobs also presented the highest prevalence rates of poor health effects. These results support the necessity of policies that encompass prevention and attention to teacher's health

Key words: Teaching. Voice disorders. Mental health. Cumulative trauma disorders. Work conditions. Bahia.

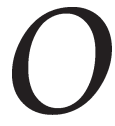

s primeiros estudos epidemiológicos sobre saúde e trabalho docente no Brasil surgiram na década de 1990. Em geral, os estudos existentes têm produzido achados bastante similares (Araújo et al., 1998; Codo et al., 1999; Silvany-Neto et al., 2000; Delcor, 2004; Reis et al., 2005; Gasparini et al., 2006; Noronha et al., 2008; Araujo et al., 2008a; Paranhos \& Araújo, 2008). Destacam-se, pela sua relevância, três grupos de problemas de saúde entre docentes: problemas relacionados à voz, problemas osteomusculares e relacionados à saúde mental. Os estudos evidenciaram também que: a) as condiçôes objetivas do trabalho confirmam a exposição dos docentes a uma série de problemas de saúde; e b) as formas como o trabalho ou as condições de trabalho se estruturam associam-se aos processos de adoecimento detectados.

No estado da Bahia, foram realizadas, desde a década de 1990, várias pesquisas sobre a saúde e trabalho de professores. Os estudos descritos aqui foram realizados por um grupo de pesquisa estruturado a partir de parceria entre o Departamento de Medicina Preventiva e Social da Universidade Federal da Bahia (UfBA) e o Núcleo de Epidemiologia da Universidade Federal de Feira de Santana (UEFS). O primeiro estudo foi realizado em 1995-1996, para atender a uma demanda do Sindicato dos Professores da Rede Particular de Ensino do Estado da Bahia (SINPRO-BA). A diretoria do Sindicato identificou, na categoria, o crescimento de um evento que foi denominado de "outubrite" - ocorrência de doenças e agravos dos professores e professoras no final do ano 
letivo: cansaço generalizado, problemas de voz, elevação da irritação e impaciência. A demanda do Sindicato era, então, avaliar o processo de desgaste gerado pelo trabalho docente na rede particular de ensino e compreender os fatores associados a esse "mal-estar" identificado pela categoria.

Este artigo apresenta um conjunto de investigaçōes epidemiológicas realizadas em populaçóes de professores das redes públicas e particular de ensino, de diferentes níveis (pré-escola, ensino fundamental I e II, ensino médio e superior), de zona urbana e rural, de três municípios do estado da Bahia. Os estudos originaram-se de demandas sindicais envolvendo, na sua execução, órgãos governamentais relacionados à temática estudada (Secretaria de Saúde e de Educação).

O objetivo deste artigo é analisar as condições de saúde e trabalho de professores, a partir de resultados de estudos epidemiológicos realizados naquele estado, identificando os problemas de saúde mais frequentes e sua associação com as características do trabalho docente.

\section{Procedimentos metodológicos}

Foram realizados oito estudos com professores de três municípios do estado da Bahia: Salvador, Feira de Santana e Vitória da Conquista, de todos os níveis de ensino: pré-escola, ensino fundamental, médio e universitário, num período de dez anos. Os estudos foram similares quanto aos procedimentos metodológicos, incluindo os instrumentos de pesquisa e técnicas de análise de dados utilizadas.

Todas as investigações aqui relatadas empregaram o desenho de estudo epidemiológico do tipo corte transversal. Este tipo de estudo caracteriza-se pela avaliação simultânea de potenciais fatores de risco e doença ou agravos à saúde, em um ponto do tempo ou num período curto de tempo.

\section{Populaçôes estudadas/critérios de seleção da amostra}

Estudo 1 - Professores da rede particular de ensino de Salvador (1996-1998): amostra de 573 professores da rede particular de ensino de Salvador, selecionada por amostragem aleatória por conglomerados (58 escolas), estratificada proporcionalmente 
pelo tamanho da escola: pequena, média e grande (Araújo et al., 1998; Silvany-Neto et al., 2000).

Estudo 2 - Professores da Universidade Federal da Bahia (2000): amostra de 257 professores, selecionados aleatoriamente do universo dos 1.728 docentes da Universidade Federal da Bahia (UFBA), estratificada proporcionalmente pelo tamanho de suas 29 unidades de ensino (Wernick, 2000).

Estudo 3 - Professores da Universidade Estadual de Feira de Santana (2000): um censo entre os 530 docentes que mantinham vínculo contratual permanente com a instituição. Foram entrevistados 314 professores (taxa de resposta de 59,2\%) (Paranhos \& Araujo, 2008).

Estudo 4 - Professores da rede particular de ensino de Vitória da Conquista (2001-2002): um censo entre os 308 docentes das dez maiores escolas particulares do município entrevistou 250 indivíduos (taxa de resposta de 81,1\%) (Delcor et al., 2004).

Estudo 5 - Professores da Rede Pública Municipal de Ensino de Vitória da Conquista (2001-2002): um censo entrevistou 808 $(83,6 \%)$ dentre os 967 professores em efetivo exercício profissional nas escolas urbanas e rurais do município (Reis et al., 2005).

Estudo 6 - Professores da rede de ensino público municipal de Salvador (2006): censo com 4.496 dos 4.697 (proporção de participação $=95,7 \%)$ professores da rede pública municipal de ensino (educação infantil e ensino fundamental) de Salvador (Souza, 2008).

Estudo 7 - Professores da rede pública municipal de ensino fundamental e médio de Salvador (2006-2007): censo com 476 professores (dentre 611 elegíveis) de escolas com 20 ou mais docentes, de 24 escolas de quatro Diretorias Regionais de Educação contíguas, distribuídas por 54 bairros da cidade do Salvador (Ceballos, 2009).

Estudo 8 - Professores da rede particular do ensino fundamental e médio, atendidos no sindicato da categoria em Salvador (2002-2003). De outubro de 2002 a outubro de 2003, 1.015 professores compareceram ao SINPRO-BA. A maioria procurou o 
Sindicato para tratar de aspectos relacionados a rescisões contratuais. Uma amostra não-aleatória, de conveniência, de 634 docentes concordou em responder a um questionário padronizado sobre suas condições de trabalho e saúde (Farias, 2004).

Um nono estudo (Porto et al., 2004), que utilizou metodologia diversa, porém complementar aos oito estudos descritos, analisou os diagnósticos médicos dados a 235 professores atendidos num serviço especializado em doenças ocupacionais da Secretaria Estadual de Saúde, em Salvador, de 1991 a 2001. O Ambulatório do Centro de Estudos da Saúde do Trabalhador (CESAT) é um serviço de referência no estado da Bahia.

\section{Instrumentos de pesquisa}

Foram utilizados questionários autoaplicáveis. As informações coletadas foram autorreferidas. Embora cada estudo tenha avaliado um conjunto diferenciado de aspectos ocupacionais e repercussóes sobre a saúde, todos os instrumentos de pesquisa utilizados incluíram blocos de questôes similares sobre: identificação geral do entrevistado (sexo, escolaridade, idade, situação conjugal) e da escola onde ele respondeu ao formulário (tempo de trabalho como professor e na escola investigada, carga horária de trabalho na semana, turno de trabalho); características do ambiente de trabalho e queixas de doenças (avaliadas por meio de uma lista de queixas e sintomas referentes à saúde física mais frequentes entre professores).

Para avaliação dos aspectos psicossociais do trabalho, usou-se o Job Content Questionnaire (JCQ) (Karasek et al., 1998; Araújo \& Karasek, 2008b). Os resultados do JCQ permitem combinar níveis de demanda psicológica e de controle sobre o próprio trabalho, constituindo diferentes situações: 1) alta exigência: combinando alta demanda e baixo controle; 2) trabalho ativo: combinando alta demanda e alto controle; 3) trabalho passivo: combinando baixa demanda e baixo controle e 4) baixa exigência: combinando baixa demanda e alto controle.

Para avaliação da saúde mental, utilizou-se um instrumento padronizado de triagem de transtornos mentais, internacionalmente adotado e validado para uma população brasileira, o Self-Reporting Questionnaire (SRQ-20) (Mari \& Williams, 1985). 
No estudo 7 , os professores submeteram-se a uma avaliação fonoaudiológica perceptivo-auditiva, realizada por especialistas. Numa etapa inicial, a qualidade vocal dos professores era classificada com o uso da escala GRBAS (Hirano, 1981), que atribui valores de 0 a 4 (ausente, leve, moderada e severa) de acordo com os parâmetros: $\mathrm{G}=$ Global impression; $\mathrm{R}=$ Roughness; $\mathrm{B}=$ Breathiness; $\mathrm{A}=$ Asthenia e $\mathrm{S}=$ Strain. Para o diagnóstico de disfonia, foi criado o Índice de Grau de Disfonia, tendo por base a escala GRBAS. Este Índice utiliza a média do somatório dos valores atribuídos aos parâmetros do R, B, A e S. Não foi utilizado o parâmetro G porque este é resultado dos demais. Considerou-se a voz como "disfônica" ou "não-disfônica". O diagnóstico fonoaudiológico final classificou a voz como "adaptada" ou "alterada", levando em consideração o GRBAS e os parâmetros: tempo máximo de fonação, características da fonação sustentada, ataque vocal, tipo e modo da dinâmica respiratória, coordenação pneumofonoarticulatória, velocidade, articulação, ressonância, pitch, loudness, modulação, som basal, tensão corporal à fonação, postura corporal à fonação e abusos vocais.

Todos os estudos apresentados aqui foram aprovados por Comitê em Pesquisa e seguiram criteriosamente as recomendações da Resolução n. 196/96.

Características sociodemográficas e do trabalho

\section{Estudo 1 - Professores da rede particular de ensino de Salvador}

A média de idade dos professores estudados foi $34,7 \pm 8,7$ anos. As mulheres representaram $74 \%$ da população estudada; $71,9 \%$ dos docentes tinham nível superior completo. $\mathrm{O}$ tempo médio na profissão foi de $11,5 \pm 7,7$ anos, $43,1 \%$ trabalhavam em mais de uma escola particular, $20,2 \%$ trabalhavam em outra escola pública e $27,7 \%$ tinham outra atividade remunerada além da atividade docente. As condições de trabalho positivas mais referidas foram: boa relação com os colegas $(97,9 \%)$, autonomia no planejamento das atividades $(89,8 \%)$ e satisfação no desempenho da atividade docente $(88,8 \%)$. As condiçôes de trabalho negativas mais referidas foram: esforço físico elevado $(78,8 \%)$, exposição à poeira e pó de giz $(62 \%)$ e fiscalização contínua do desempenho $(61,9 \%)$. 
Estudo 2 - Professores da Universidade Federal da Bahia

Os homens representaram $55,3 \%$ da população estudada. A média de idade foi de 46 anos. Mais da metade dos professores referiu problemas na estrutura física dos locais de trabalho (ventilação, ergonomia das carteiras e mesas, acústica das salas de aula e nível elevado de ruído). Os riscos mais frequentemente referidos foram os de violência contra o patrimônio $(66,6 \%)$, violência pessoal - roubos, furtos, estupro $(57,3 \%)$ e exposição ao calor $(63,0 \%)$. A insatisfação com o salário foi referida por $84,5 \%$ da amostra.

\section{Estudo 3 - Professores da Universidade Estadual de Feira de Santana}

Registrou-se ligeiro predomínio do sexo feminino (52,9\% do total). A média de idade foi de 41,9 99,2 anos, sendo a faixa etária mais frequente de 30 a 39 anos (39,6\%). O tempo médio de trabalho como docente foi $9,6 \pm 7,3$ anos. Dentre as cargas de trabalho destacaram-se, entre as cargas ergonômicas: permanecer em pé por longos períodos $(82,1 \%)$, escrever em quadro de giz $(79,4 \%)$, posição inadequada do corpo $(59,3 \%)$ e posição inadequada da cabeça $(47,4 \%)$; entre as cargas físicas: ventilação inadequada das salas de aulas $(69,1 \%)$, calor $(53,1 \%)$ e ruído (44,4\%); entre as cargas mecânicas: carregar material didático $(76,5 \%)$ e entre as cargas químicas: exposição ao pó de giz $(77,9 \%)$ e poeira $(42,2 \%)$. Destacaram-se, entre os aspectos da organização do trabalho: exigência de concentração por longos períodos $(76,9 \%)$, tempo insuficiente para a realização das tarefas e estudo $(55,2 \%)$ e ritmo de trabalho acelerado $(52,3 \%)$.

\section{Estudo 4 - Professores da rede particular de ensino de Vitória da Conquista}

As mulheres predominaram $(82,8 \%)$. A média de idade foi de $34,5 \pm 7,5$ anos; $72,1 \%$ tinham nível de escolaridade superior (em curso ou completo). O tempo médio de trabalho como professor foi de $11,4 \pm 6,9$ anos. A carga total média de trabalho semanal (todas as escolas) somava 34,3 $\pm 16,9$ horas. Em média, os professores tinham 3,9 turmas, número médio de 30,1 $\pm 9,1$ alunos por turma; $59,3 \%$ referiram trabalhar em outra escola e 9,2\% em mais de duas escolas; 19,9\% 
mantinham outra atividade remunerada além da docência. A permanência de pé durante o período de aula foi referida por $96,7 \%$ dos professores. Dentre as características do trabalho destacaram-se: ritmo acelerado $(67,9 \%)$, manutenção de posição inadequada e incômoda do corpo $(65,4 \%)$, posições da cabeça e braços inadequadas e incômodas $(53,4 \%)$ e longos períodos de intensa concentração em uma mesma tarefa $(51,9 \%)$.

\section{Estudo 5-Professores da rede pública municipal de ensino de Vitória da Conquista}

Dos 808 professores estudados, 55,8\% ensinavam em escolas da zona urbana e $44,2 \%$ na zona rural; $94 \%$ eram mulheres, com idade variando de 19 a 60 anos, média de idade de 34,2 $\pm 8,5$ anos. Apenas $32 \%$ possuíam nível superior. O tempo médio de trabalho dos professores foi de $10,4 \pm 6,7$ anos; $85,2 \%$ tinham vínculo de trabalho estável e $14,8 \%$ contrato de trabalho provisório. A modalidade de ensino predominante foi a fundamental I (64,7\%). A média de turmas por professor foi de 2,4, com média de 29,4 7,6 alunos por sala de aula. A carga horária total média de trabalho foi $38,8 \pm 11,1$ horas por semana. Cerca de um terço $(32,1 \%)$ trabalhava em mais de uma escola. Além das atividades de ensino, 5,8\% dos professores mantinham outra atividade remunerada em paralelo à docência.

\section{Estudo 6-Professores da rede de ensino público municipal de Salvador}

Dos 4.496 docentes da rede municipal de ensino de Salvador estudados, 92,0\% eram do sexo feminino; $80,3 \%$ possuíam nível superior

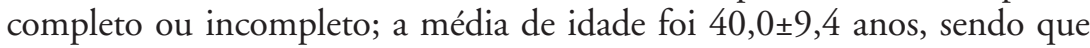
$47,9 \%$ tinham 40 anos ou mais de idade, variando de 18 anos a 69 anos. O tempo de trabalho como professor variou de 1 a 45 anos (média de $14,4 \pm 8,4$ anos). A maioria ensinava apenas no fundamental I $(68,3 \%)$. Os professores tinham, em média, $2,1 \pm 1,7$ turmas e $31,2 \pm 5,8$ alunos por sala de aula; $52,7 \%$ trabalhavam 40 ou mais horas semanais. $\mathrm{O}$ trabalho em mais de uma escola da rede municipal foi referido por $14,2 \%$, enquanto $32,0 \%$ relataram trabalhar em escola de outra rede de ensino e $11,2 \%$ em outra atividade além da docência. 
Dentre as escolas da rede municipal de Salvador, foi selecionada aquela com a maior proporção de queixas relacionada à temperatura, ruído e iluminação, para a realização de medidas objetivas desses parâmetros ambientais em sala de aulas. Os níveis de ruído variaram de $80,25 \mathrm{~dB}(\mathrm{~A})$ a $86,46 \mathrm{~dB}(\mathrm{~A})$. Os índices de conforto térmico apresentaram resultados acima da faixa de referência. Os níveis de iluminância das salas foram considerados insatisfatórios (a média variou de 324,50 a 571,22 lux). Dificuldade no trabalho em sala de aula foi referida por 75,9\% dos professores entrevistados (Farias, 2009).

\section{Estudo 7-Professores da rede pública municipal de ensino fundamental e médio de Salvador}

Dos 476 docentes da rede municipal de ensino fundamental e médio de Salvador: $82,9 \%$ eram mulheres, $47,1 \%$ estavam casadas ou em união estável, $36,8 \%$ eram solteiras, $14,4 \%$ separadas/divorciadas e $1,7 \%$ viúvas. A idade variou de 21 a 65 anos, sendo a média de $40,7 \pm 9,5$ anos. O nível de escolaridade foi elevado: 44,5\% tinham especialização, $32,8 \%$ superior completo, $10,9 \%$ cursavam o nível superior; $10,5 \%$ tinham magistério e $1,3 \%$, apenas o nível médio. Com relação às características gerais de trabalho, o tempo médio como professor foi de 12,5 $\pm 9,7$ anos entre as mulheres e 7,2 $\pm 9,4$ entre os homens. Ensinavam no ensino infantil, $15,2 \%$ dos docentes; $59,7 \%$ ensinavam no ensino fundamental I ( $1^{\mathrm{a}}$ a $4^{\mathrm{a}}$ série), $40,3 \%$ no fundamental II $\left(5^{\mathrm{a}}\right.$ a $8^{\mathrm{a}}$ séries) e $15,7 \%$ no ensino médio. Alguns docentes ensinavam em diversos níveis, o que explica a soma dos percentuais acima exceder $100 \%$. Com até $20 \mathrm{~h}$ horas semanais de trabalho estavam 26,4\% dos docentes; $52,6 \%$ trabalhavam de 21 a 40 horas e $21 \%$ de 41 a 60 horas semanais (18,6\% referiram carga horária semanal de 60 horas); 53,3\% trabalhavam em duas ou mais escolas e $20,1 \%$ tinham outra atividade remunerada não-docente.

Estudo 8 - Professores da rede particular do ensino fundamental e médio, atendidos no sindicato da categoria em Salvador

Entre os 634 professores, a maioria era do sexo feminino $(76,1 \%)$, com média de idade de 34,1 7 ,9 anos; $82,5 \%$ tinham até 40 anos; 
$81,7 \%$ tinham nível superior completo ou em curso (sendo 23\% com especialização, 4,6\% com mestrado e $0,6 \%$ com doutorado). O tempo médio de trabalho como professor foi de $11,0 \pm 6,7$ anos. A maioria dos professores $(52,4 \%)$ tinha de 6 a 15 anos de profissão. A carga horária semanal média de trabalho docente foi de $27,3 \pm 15,1$ horas, com média de 4,2 turmas por docente. O emprego em mais de uma escola foi referido por $33,8 \%$ dos professores. Além das atividades na área educacional, $17,5 \%$ dos professores desenvolviam outras atividades remuneradas, fora da esfera docente. Dentre as características do ambiente do trabalho, foram destacados: inexistência de local para descanso dos professores $(55,7 \%)$; pó de giz na sala de aula $(54,9 \%)$; local da aula ruidoso (45,2\%); acústica da sala deficiente; ambiente estressante $(25,7 \%)$; eco na sala de aula $(19,9 \%)$ e temperatura muito fria $(7,6 \%)$.

\section{Condiçõos de trabalho e saúde}

\section{Problemas vocais}

A Tabela 1 resume as prevalências de queixas de problemas vocais referidos pelos professores em oito diferentes estudos. Chamam atenção as elevadas prevalências das queixas de dor de garganta, rouquidão, perda temporária da voz e diagnóstico médico referido de calo nas cordas vocais.

No estudo 6, 21,7\% dos docentes da rede municipal de ensino de Salvador apresentavam incapacidade vocal, medida pelo questionário Voice Handicap Index (VHI-10). Esta incapacidade vocal estava associada ao Índice de Esforço Vocal Profissional, que é o produto de anos trabalhados como professor multiplicado pela carga horária semanal média (Sampaio, 2009).

No estudo 7, a prevalência de problemas vocais em professores de Salvador foi avaliada por fonoaudióloga, além das queixas referidas pelos professores, em questionários individuais autoaplicados. A análise perceptivo-auditiva, feita pelas fonoaudiólogas, classificou $25,4 \%$ dos professores como tendo voz "disfônica" e 55,1\% como tendo voz "alterada".

Diagnóstico médico de calo nas cordas vocais foi dado em 10,8\% dos 235 professores atendidos no ambulatório de doenças ocupacionais do CESAT, em Salvador (Porto et al., 2007). 


\section{Tabela 1}

Problemas vocais (em \%) referidos por professores em oito estudos (estado da Bahia, 1996-2007).

\begin{tabular}{|c|c|c|c|c|}
\hline Estudo (N) & $\begin{array}{c}\text { Dor de } \\
\text { garganta }^{a}\end{array}$ & Rouquidāo $^{a}$ & $\begin{array}{c}\text { Perda } \\
\text { temporária } \\
\text { da voz }\end{array}$ & $\begin{array}{l}\text { Diagnóstico } \\
\text { médico calo de } \\
\text { corda vocal }\end{array}$ \\
\hline 1 - Rede particular, Salvador (573) & 49,5 & 43,5 & 22,6 & 12,0 \\
\hline $\begin{array}{l}2 \text { - Universidade Federal da Bahia } \\
(257)\end{array}$ & 24,8 & 25,8 & $7,5 \%$ & 2,7 \\
\hline $\begin{array}{l}3 \text { - Universidade Estadual de Feira } \\
\text { de Santana (314) }\end{array}$ & 20,2 & 18,5 & 5,4 & 5,1 \\
\hline $\begin{array}{l}4 \text { - Rede particular Vitória da } \\
\text { Conquista (250) }\end{array}$ & 45,7 & $59,2^{c}$ & 22,5 & 12,0 \\
\hline $\begin{array}{l}5 \text { - Rede pública Vitória da } \\
\text { Conquista }(808)\end{array}$ & 52,4 & $58,6^{c}$ & 23,4 & 11,0 \\
\hline $\begin{array}{l}6 \text { - Rede pública municipal, } \\
\text { Salvador }(4.496)\end{array}$ & 24,1 & 23,9 & 5,3 & 18,9 \\
\hline $\begin{array}{l}7 \text { - Escolas }>20 \text { docentes, rede } \\
\text { pública municipal, Salvador ( } 476)\end{array}$ & $42,2^{b}$ & $51,8^{b}$ & $13,7^{\mathrm{b}}$ & -- \\
\hline $\begin{array}{l}8 \text { - Atendidos no Sindicato, rede } \\
\text { particular, Salvador ( } 634)\end{array}$ & $49,4^{\mathrm{b}}$ & $89,6^{c}$ & 40,0 & 12,0 \\
\hline
\end{tabular}

a - "Frequente" ou "Muito frequente", exceto quando existir observação;

b - Queixa atual;

c- Rouquidão nos últimos 6 meses, em vez de frequente/muito frequente.

A análise de relação entre condições de trabalho e problemas vocais evidencia que tais características podem influenciar na saúde vocal docente. Avaliando-se, no estudo 5, queixa de calo nas cordas vocais, observou-se associação positiva, estatisticamente significante, com ter e" 5 anos como docente, trabalhar em mais de uma escola, trabalhar em outra atividade além da docência e fazer força para falar (Araújo et al., 2008a).

\section{Problemas osteomusculares}

A Tabela 2 resume as prevalências de queixas de problemas osteomusculares referidos pelos professores de seis diferentes estudos. Diagnóstico médico de LER/DORT foi dado em 12,4\% dos professores 
atendidos no ambulatório do Sindicato da rede privada (Farias, 2004) e em 53,6\% dos 235 professores atendidos no ambulatório de doenças ocupacionais do CESAT, em Salvador (Porto et al., 2007).

\section{Tabela 2}

Problemas osteomusculares (em \%) referidos por professores em seis estudos (estado da Bahia, 1996-2007).

\begin{tabular}{|l|c|c|c|c|}
\hline \multicolumn{1}{|c|}{ Estudo (N) } & $\begin{array}{c}\text { Dor nos } \\
\text { braços }^{\mathrm{a}}\end{array}$ & $\begin{array}{c}\text { Dor nas } \\
\text { pernas }^{\mathrm{a}}\end{array}$ & Dor nas costas ${ }^{\mathrm{a}}$ & $\begin{array}{c}\text { Diagnóstico } \\
\text { médico de } \\
\text { LER/DORT }\end{array}$ \\
\hline $\begin{array}{l}\text { 1 - Rede particular, Salvador } \\
\text { (573) }\end{array}$ & 25,0 & 47,1 & 45,0 & $-2-$ \\
$\begin{array}{l}\text { - Universidade Federal da } \\
\text { Bahia (257) }\end{array}$ & 18,8 & 36,1 & 37,0 & 7,8 \\
$\begin{array}{l}3 \text { - Universidade Estadual de } \\
\text { Feira de Santana (314) }\end{array}$ & 16,7 & 28,3 & 30,8 & 16,4 \\
$\begin{array}{l}4 \text { - Rede particular, Vitória da } \\
\text { Conquista (250) }\end{array}$ & 52,1 & 47,5 & 51,4 & 14,6 \\
$\begin{array}{l}\text { 5 - Rede pública, Vitória da } \\
\text { Conquista (808) }\end{array}$ & 67,0 & 63,7 & 62,6 & 5,2 \\
$\begin{array}{l}\text { 6 - Rede pública municipal, } \\
\text { Salvador (4.496) }\end{array}$ & 23,7 & 41,0 & 41,0 & \\
\hline
\end{tabular}

a - "Frequente" ou "Muito frequente".

No estudo 6, 55\% dos entrevistados referiram sentir "frequentemente" ou "muito frequentemente" dor músculo-esquelética em alguma região do corpo. A prevalência de queixas músculo-esqueléticas entre os 4.237 professores foi de $41,1 \%$ para membros inferiores, $41,1 \%$ para costas/coluna e $23,7 \%$ para membros superiores. Análises multivariadas revelaram que a dor nos membros inferiores estava associada ao número de turmas maior ou igual a 2 , a trabalhar em mais de uma escola, possuir outra atividade remunerada além da docente e ao excesso de esforço físico no trabalho; dor nos membros superiores associouse ao tempo de trabalho como professor maior ou igual a 14 anos, ao número de alunos maior ou igual a 30 e ao excesso de esforço físico no trabalho; dor nas costas/coluna associou-se ao número de turnos de 
trabalho maior ou igual a 2, número de turmas maior ou igual a 2, carga horária de trabalho maior ou igual a 40 horas, mobiliário inadequado e ao excesso de esforço físico no trabalho (Ribeiro, 2009).

\section{Saúde mental}

Os estudos evidenciam que o adoecimento psíquico constitui um problema de significativa relevância entre os docentes, tanto no que diz respeito às referências de sintomas de cansaço mental, nervosismo (Reis et al., 2006), quanto na identificação de transtornos mentais comuns (TMC). ${ }^{1}$ As prevalências de TMC foram elevadas em todas as populações estudadas, como mostram os dados da Tabela 3: os transtornos mentais comuns atingiram, pelo menos, cerca de $1 / 5$ dos entrevistados, como no estudo da UEFS/UfBA e rede particular de Salvador (em 1998), ou alcançaram proporçôes alarmantes, como no estudo de Vitória da Conquista, onde se observou prevalência global de 55,4\%. Observouse também que as mulheres eram mais atingidas que os homens, embora as diferenças entre as prevalências sejam mais expressivas em algumas populações do que em outras.

\section{Tabela 3}

Prevalência (\%) de transtornos mentais comuns segundo gênero entre professores em oito estudos (estado da Bahia, 1996-2007).

\begin{tabular}{|l|c|c|c|}
\hline \multicolumn{1}{|c|}{ Estudo (N) } & Mulheres & Homens & Global \\
\hline 1 - Rede particular, Salvador (573) & 21,4 & 17,0 & 20,1 \\
2 - Universidade Federal da Bahia (257) & 20,0 & 17,6 & 18,7 \\
3 - Universidade Estadual de Feira de Santana (314) & 26,4 & 11,2 & 19,3 \\
4 - Rede particular, Vitória da Conquista (250) & 45,5 & 21,4 & 45,5 \\
5 - Rede pública, Vitória da Conquista (808) & 56,8 & 35,6 & 55,4 \\
6 - Rede pública municipal, Salvador (4.496) & 22,8 & 19,2 & 22,5 \\
7 - Escolas >20 docentes, rede pública municipal, Salvador (476) & 30,7 & 29,3 & 29,6 \\
8 - Atendidos no Sindicato, rede particular, Salvador (634) & 24,9 & 19,4 & 23,6 \\
\hline
\end{tabular}

Educ. Soc., Campinas, vol 30, n. 107, p. 427-449, maio/ago. 2009 
Características do trabalho docente, como trabalho repetitivo, insatisfação no desempenho das atividades, desgaste nas relações professor-aluno, ambiente intranquilo, falta de autonomia no planejamento das atividades, ritmo acelerado de trabalho, desempenho das atividades sem materiais e equipamentos adequados e salas inadequadas associaram-se, positivamente, a níveis estatisticamente significantes, aos transtornos mentais identificados nos estudos realizados. Aspectos psicossociais também foram relevantes à saúde mental dos docentes. Trabalho realizado em situação de alta exigência (envolvendo altas demandas psicológicas e baixo nível de controle) estava associado à maior prevalência de TMC. Análises mais detalhadas de associação entre características do trabalho e efeitos sobre a saúde mental dos professores, verificada nos estudos aqui descritos, podem ser encontradas em publicações específicas sobre o tema (Araújo et al., 2003; Delcor et al., 2004; Reis et al., 2005; Reis et al., 2006; Porto et al., 2006).

\section{Aspectos psicossociais do trabalho e saude}

Alguns dos estudos realizados na Bahia exploraram a relação entre aspectos psicossociais do trabalho e efeitos sobre a saúde (TMC, LER, varizes, gastrite, calos nas cordas vocais e rouquidão/alteração vocal). A Tabela 4 apresenta os problemas de saúde de acordo com situaçôes de trabalho mensuradas pelo modelo demanda-controle (Karasek et al., 1998). Para todos os efeitos investigados, as maiores prevalências foram encontradas na situação de trabalho em alta exigência (baixo controle sobre o próprio trabalho e alta demanda psicológica), sugerindo que a exposição a esta situação de trabalho pode representar condição desfavorável à saúde dos docentes.

Os estudos que investigaram, especificamente, associação entre os aspectos psicossociais do trabalho e saúde nas análises aqui descritas, com emprego de métodos de análise sofisticados, envolvendo modelos multivariados, confirmaram associação positiva entre trabalho em alta exigência e TMC (Reis et al., 2005; Porto et al., 2006) e com alteração vocal, avaliada por fonoaudiólogas (Thomé, 2007), mesmo após ajuste por variáveis de confusão. 


\section{Tabela 4}

Prevalência (\%) de problemas de saúde, segundo grupos do modelo demanda-controle entre professores

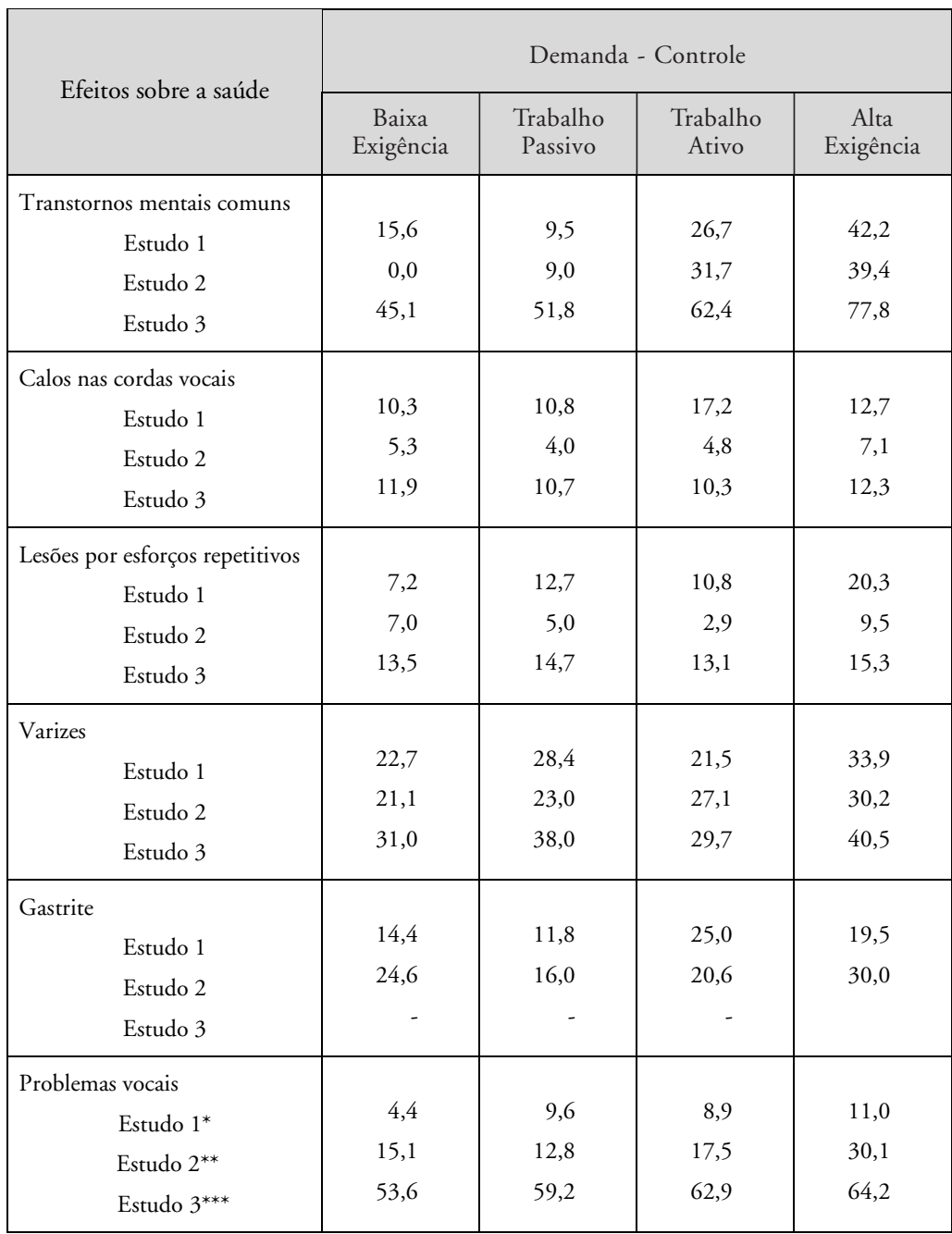

* Alteração constante da voz/** Rouquidão/*** Rouquidão nos últimos 6 meses

Rede particular de Salvador (N=634; Estudo 1, 2003), Universidade Estadual de Feira de Santana ( $N=314$; Estudo 2, 2001) e rede pública municipal de Vitória da Conquista ( $N=808$, Estudo 3, 2001).

Educ. Soc., Campinas, vol 30, n. 107, p. 427-449, maio/ago. 2009

Disponível em <http://www.cedes.unicamp.br> 


\section{Trabalho doméstico: elemento relevante para a análise da relação entre o trabalho e a saúde das mulheres}

Como descrito no perfil dos grupos estudados, a categoria docente é composta majoritariamente por mulheres, chegando a representar, em algumas populaçóes e níveis de ensino, mais de $90 \%$ do total. Tal fato suscita a necessidade de incluir, na análise da relação entre trabalho e saúde, a abordagem das relaçôes de gênero.

Os resultados dos nossos estudos revelaram características e condições do trabalho bastante diferenciadas para os homens e as mulheres na atividade docente. Os dados referentes à análise de diferenciais de gênero no estudo de professores da rede municipal de Vitória da Conquista são ilustrativos da situação, também presente nos demais estudos. Foram observados níveis distintos de escolaridade segundo gênero: entre os homens, 42,6\% tinham nível superior completo, enquanto apenas 18,1\% das mulheres tinham esse mesmo nível. Com relação ao nível das turmas, $40,0 \%$ dos homens ensinavam no fundamental II, enquanto, entre as mulheres, o percentual foi de apenas $18,5 \%$. A situação em relação ao trabalho em outra escola, que pode ser indicativo de diferença na qualificação ou nas oportunidades de inserção no mercado de trabalho, foi mais frequente entre os homens $(63,0 \%)$ do que entre as mulheres $(32,7 \%)$. Com relação às características do trabalho, também se observaram diferenças: as mulheres apresentavam quase duas vezes mais tempo como docente do que os homens (10,6 anos contra 5,8 anos), tinham carga horária total de trabalho maior do que a dos homens (média de 32,3 horas para as mulheres contra 28,9 horas semanais para os homens), o mesmo acontecendo com a carga horária em sala de aula (28,7 contra 24,6 horas); contudo, a renda era mais elevada entre os homens ( $R \$ 553,30$ contra $R \$ 472,10$, em valores de 2001). Ou seja, mesmo se tratando de uma população tipicamente feminina, observam-se desvantagens para as mulheres.

Estes resultados delineiam contornos desiguais nas relações de gênero, nas características do trabalho docente, apontando a pertinência de se levar em consideração tais diferenciações na análise de trabalho e saúde na escola.

Outra dimensão de diferenciações da carga de trabalho de homens e mulheres pode ser observada com relação ao trabalho doméstico. 
No estudo da rede particular de Vitória da Conquista, a sobrecarga doméstica (medida por atividades domésticas como lavar, passar, cozinhar e limpar, ponderada pelo número dos moradores do domicílio) foi alta para apenas 3\% dos homens e 33\% entre as mulheres, revelando que a responsabilidade pelas tarefas domésticas é atribuição ainda restrita às mulheres. Tal achado sustenta a necessidade de que seja computada a carga total de trabalho (trabalho profissional e doméstico) para homens e mulheres, de modo a permitir avaliação mais precisa dos tipos de exposiçôes a que se encontram submetidos e de sua duração.

Em professores de Vitória da Conquista, a maioria dos problemas de saúde investigados foi mais frequente entre as mulheres (Araújo et al., 2006). As principais queixas de adoecimento referidas foram similares para homens e mulheres. Entretanto, o consumo abusivo de álcool foi mais frequente entre os homens $(6,4 \%)$ do que entre as mulheres $(1,2 \%)$.

\section{Alguns limites da pesquisa}

Inicialmente, cabe destacar a abrangência dos resultados aqui descritos: este artigo apresentou um conjunto de investigaçôes desenvolvidas durante uma década no estado da Bahia, incluindo diferentes redes de ensino, todos os níveis de ensino (da educação infantil ao nível superior), envolvendo docentes de zona urbana e rural; constitui, portanto, um rico corpo de evidências empíricas sobre as condições de saúde e trabalho docente, ainda que se considere o caráter local das populações sob estudo.

Contudo, na análise dos resultados apresentados é importante considerar alguns limites dos estudos realizados. A primeira limitação refere-se ao fato da análise ter sido feita em um único ponto do tempo: não permitindo estabelecer, temporalmente, se foi a situação de trabalho que produziu o adoecimento ou se foi o adoecimento que deslocou o professor para uma situação de exposição. Todavia, pela natureza dos eventos estudados, parece ser mais consistente a hipótese de que a exposição pode ter produzido o adoecimento. De qualquer modo, o caráter simultâneo de avaliação da exposição e da doença não permite conclusão mais precisa de causalidade.

Em estudos ocupacionais, a questão relativa ao chamado efeito do trabalhador sadio é outra limitação importante: encontram-se em efetivo 
exercício profissional as pessoas mais aptas, que foram previamente selecionadas como sadias; assim, o estudo de trabalhadores em pontos específicos do tempo tende a analisar apenas aqueles que permaneceram na atividade (foram selecionados e permaneceram aptos ao trabalho). Além disso, pessoas que adoeceram e abandonaram a profissão também não são incluídas no estudo. Esses aspectos podem subestimar as medidas produzidas. Contudo, mesmo que tais distorções de subestimação possam ter ocorrido, os resultados obtidos revelam uma situação bastante preocupante, com identificação de elevadas prevalências de queixas de doença e agravos à saúde.

A análise dos resultados obtidos, portanto, deve ser feita considerando-se as limitações aqui descritas.

\section{Considerações finais}

O perfil da categoria estudada revelou predomínio de mulheres, embora possa ser assinalado que a participação masculina aumentou, significativamente, nos níveis mais elevados de ensino (na UFBA, por exemplo, representou mais da metade da população). Outras características comuns às populações estudadas referem-se à existência de múltiplos empregos, elevada carga horária total de trabalho e elevadas demandas psicológicas e físicas. As populações estudadas eram relativamente jovens. Portanto, as elevadas frequências de problemas de saúde observados podem ser indicativas de processos de desgaste precoce e acentuados nessa categoria, o que reforça a relevância de que novos estudos explorem mais detalhadamente os aspectos apontados.

Os achados relativos à saúde docente foram similares aos estudos realizados com docentes em outros locais no Brasil (Gasparini, 2005: Carvalho, 2006; Gasparini et al. 2006; Leite \& Souza, 2007; Penteado \& Pereira, 2007; Noronha, 2008), destacando-se os problemas osteomusculares, de voz e relativos à saúde mental. Estes problemas se associam à postura corporal, ao uso intensivo da voz e às formas de organização do trabalho, respectivamente.

A elevada prevalência dos problemas de saúde identificados associou-se à elevada demanda psicológica envolvida na execução das atividades, baixo controle sobre o próprio trabalho, maior tempo de trabalho como professor, elevada carga horária semanal, múltiplos empregos e 
uma série de características relativas ao ambiente e organização do trabalho docente, tais como ritmo de trabalho, ambiente em condiçôes inadequadas, relações estressantes entre professor, entre outros aspectos.

As mulheres apresentaram maiores prevalências na maioria dos problemas de saúde investigados. A despeito da reconhecida maior referência aos problemas de saúde entre mulheres (Araujo et al., 2006), o que pode ter contribuído para superestimar as prevalências observadas entre as mulheres, os achados de maior proporção de adoecimento entre as professoras reforçam a necessidade de que as diferenças no trabalho de homens e mulheres sejam avaliadas para melhor delimitação de suas características, bem como se deve incorporar à análise as atividades laborais realizadas fora do trabalho profissional, como o trabalho doméstico, para uma avaliação mais satisfatória e ampla das relações entre trabalho e saúde.

Os estudos realizados em professores da Bahia revelam as importantes contribuiçóes dos aspectos relacionados ao ambiente escolar e à organização do trabalho docente para a ocorrência dos diferentes efeitos investigados sobre a saúde. Os estudos, apesar de terem caráter exploratório, permitiram evidenciar que trabalhos docentes com maiores exigências (em termos de volume e de extensão no tempo) estavam associados às prevalências mais elevadas de queixas de doença.

Os resultados delimitam a relevância dos problemas de saúde entre docentes, evidenciando a premência de maior atenção às formas de organização do trabalho docente, de estruturação do ambiente na escola e de estabelecimento de políticas de proteção à saúde. Os primeiros desafios a serem enfrentados referem-se ao redimensionamento das questôes de saúde junto aos próprios professores.

A saúde docente é uma questão ainda periférica nas preocupações do setor da educação, tanto na visão da gestão escolar, quanto na dos docentes. Acostumado a cuidar do outro, o docente tem dificuldades de voltar o olhar para si mesmo, para o seu bem-estar e, especialmente, para sua saúde. Sintomas de adoecimento são negados ou minimizados; apenas quando um problema atinge um patamar de severidade elevada é que se atenta para a sua existência. Assim, em geral, a doença é vivenciada como um processo individual, uma inadequação ou dificuldade pessoal. $\mathrm{O}$ caráter coletivo do adoecer na atividade docente, associado à determinada configuração do trabalho, ainda é um 
olhar a ser construído nesta categoria profissional (Araújo et al., 1998). A ausência de reconhecimento do adoecimento e da sua relação com o trabalho tem como maior consequência a manutenção de situações prejudiciais à saúde, o que, por sua vez, colabora para o aumento do adoecimento na categoria e para o abandono da profissão.

Recebido em junho de 2009 e aprovado em julho de 2009.

\section{Nota}

1. Os relatórios de pesquisa e os artigos inicialmente publicados adotaram a terminologia de "distúrbios psíquicos menores" (DPM) para designar a sintomatologia identificada pelo SRQ20. Atualmente, adotamos a denominação "transtornos mentais comuns" (TMC) como a mais apropriada ao tipo de evento mensurado pelo instrumento adotado e de uso corrente na literatura mais recente no Brasil. Os transtornos mentais comuns, expressão criada por Goldberg e Huxley (1992), caracterizam-se por sintomas como insônia, fadiga, irritabilidade, esquecimento, dificuldade de concentração e queixas somáticas. Maior detalhamento pode ser obtido em Goldberg e Huxley (1992).

\section{Referências}

ARAÚJO, T.M. et al. Condiçôes de trabalho e saúde dos professores da rede particular de ensino de Salvador-Bahia. Salvador: Sindicato dos Professores do Estado da Bahia, 1998.

ARAÚJO, T.M. et al. Trabalho docente e sofrimento psíquico: um estudo entre professores de escolas particulares de Salvador, Bahia. Revista da FAEEBA, Salvador, v. 12, n. 20, p. 485-495, 2003.

ARAÚJO, T.M. et al. Estresse ocupacional e saúde: contribuiçôes do Modelo Demanda-Controle. Ciência \& Saúde Coletiva, Rio de Janeiro, v. 8, n. 4, p. 991-1003, 2003.

ARAÚJO, T.M. et al. Diferenciais de gênero no trabalho docente e repercussões sobre a saúde. Ciência \& Saúde Coletiva, Rio de Janeiro, v. 11, n. 4, p. 1117-1129, 2006.

ARAÚJO, T.M. et al. Fatores associados a alterações vocais em professoras. Cadernos de Saúde Pública, Rio de Janeiro, v. 24, n. 6, p. 12291238, 2008. 
ARAÚJO, T.M.; KARASEK, R. Validity and reliability of the job content questionnaire in formal and informal jobs in Brazil. Scandinavian Journal of Work Environment \& Health, Helsinki, v. 34, supl. 6, p. 52-59, 2008.

CARVALHO, A.J.F.P.; ALEXANDRE, N.M.C. Síntomas osteomusculares em profesores do ensino fundamental. Revista Brasileira de Fisioterapia, São Carlos, v. 10, n. 1, p. 35-41, 2006.

CEBALLOS, A.G.C. Apoio social e fatores associados à disfonia em professores. 2009. 67f. Tese (Doutorado) - Instituto de Saúde Coletiva, Universidade Federal da Bahia, Salvador.

CODO, W. (Org.). Educação: afeto e carinho. Petropólis: Vozes; CNTE, 1999.

DELCOR, N.S. et al. Condições de trabalho e saúde dos professores da rede particular de ensino de Vitória da Conquista, Bahia, Brasil. Cadernos de Saúde Pública, Rio de Janeiro, v. 20, n. 1, p. 187-196, 2004.

FARIAS, P.M. Condiçôes do ambiente de trabalho do professor: avaliação em uma escola municipal em Salvador- Bahia. 2009. 223f. Dissertação (Mestrado) - Faculdade de Medicina, Universidade Federal da Bahia, Salvador.

FARIAS, T.F. Voz do professor: relação saúde e trabalho 2004. $158 \mathrm{f}$. Dissertação (Mestrado) - Faculdade de Medicina, Universidade Federal da Bahia, Salvador.

GASPARINI, S.M.; BARRETO, S.M.; ASSUNÇÃO, A.A. O professor, as condições de trabalho e os efeitos sobre sua saúde. Educação \& Pesquisa, São Paulo, v. 31, n. 2, p. 189-199, 2005.

GASPARINI, S.M.; BARRETO, S.M.; ASSUNÇÃO, A.A. Prevalência de transtornos mentais comuns em professores da rede municipal de Belo Horizonte, Minas Gerais, Brasil. Cadernos de Saúde Pública, Rio de Janeiro, v. 22, n. 12, p. 2679-91, 2006.

GOLDBERG, D.; HUXLEY, P. Common mental disorders: a bio-social model. London: Tavistock Publications; New York: Routledge, 1992. 
HIRANO, M. Clinical examination of voice. New York: Springer, 1981.

LEITE, M.P.; SOUZA, A.N. Condições de trabalho e suas repercussões na saúde de professores da educação básica no Brasil, Estado da Arte. São Paulo: FUNDACENTRO, 2007. Disponível em: <http://www.fundacentro.gov.br/ dominios/CTN/anexos/relatorio_unicamp_corrigido.pdf>.

MARI, J.J.; WILLIAMS, P. A comparison of the validity of two psychiatric screening questionnaires (GHQ-12 and SRQ-20) in Brazil, using Relative Operating Characteristic (ROC) analysis. Psychological Medicine, Cambridge, v. 15, p. 651-659, 1985.

NORONHA, M.M.B.; ASSUNÇÃO, A.A.; OLIVEIRA, D.A. O sofrimento no trabalho docente: o caso das professoras da rede pública de Montes Claros, MG. Trabalho, Educação \& Saúde, Rio de Janeiro, v. 6, n. 1, p. 65-86, 2008.

PARANHOS, I.S.; ARAÚJO, T.M. Interrelación entre trabajo docente y salud en una institución de educación superior. In: Oliveira, D.A.(Org.). Politicas educativas y trabajo docente en América Latina. Lima: Universidad de Ciencias y Humanidades, 2008. p. 151-182.

PENTEADO, R.Z.; PEREIRA, I.M.T.B. Qualidade de vida e saúde vocal de professores. Revista de Saúde Pública, São Paulo, v. 41, n. 2, p. 236-243, 2007.

PORTO, L.A. et al. Doenças ocupacionais em professores atendidos pelo Centro de Estudos da Saúde do Trabalhador (CESAT). Revista Baiana Saúde Pública, Salvador, v. 28, n. 1, p. 33-49, 2004.

PORTO, L.A. et al. Associação entre distúrbios psíquicos e aspectos psicossociais do trabalho de professores. Revista de Saúde Pública, São Paulo, v. 40, n. 5, p. 818-826, 2006.

REIS, E.J.F.B. et al. Trabalho e distúrbios psíquicos em professores da rede municipal de Vitória da Conquista, Bahia, Brasil. Cadernos Saúde Pública, Rio de Janeiro, v. 21, n. 5, p. 1480-1490, 2005.

REIS, E.J.F.B. et al.. Docência e exaustão emocional. Educação \& Sociedade, Campinas, v. 27, n. 94, p. 251-275, 2006. 
RIBEIRO, I.Q.B. Fatores de risco ocupacionais para dor músculo-esquelética em professores. 2009. 73f. Dissertação (Mestrado) - Faculdade de Medicina, Universidade Federal da Bahia, Salvador.

SAMPAIO, M.C. Incapacidade vocal em professores. 2009. 65f. Dissertação (Mestrado) - Faculdade de Medicina, Universidade Federal da Bahia, Salvador.

SILVANY-NETO, A.M. et al. Condições de trabalho e saúde dos professores da rede particular de ensino de Salvador. Revista Baiana de Saúde Pública, Salvador, v. 24, n. 1/2, p. 42-56, 2000.

SOUZA, C.L. Distúrbio vocal em professores da educação básica da cidade do Salvador-BA. 2008. 91f. Dissertação (Mestrado) - Instituto de Saúde Coletiva, Universidade Federal da Bahia, Salvador.

THOMÉ, C.R. A voz do professor: relação entre distúrbio vocal e fatores psicossociais do trabalho. 2007. 108f. Dissertação (Mestrado) Pontifícia Universidade Católica de São Paulo, São Paulo.

WERNICK, R. Condições de saúde e trabalho dos docentes da Universidade Federal da Bahia, Salvador-BA. 2000. 56f. Dissertação (Mestrado) - Instituto de Saúde Coletiva, Universidade Federal da Bahia, Salvador. 